\title{
New Coronavirus (SARS-CoV-2) Crossing Borders Beyond Cities, Nations, and Continents: Impact of International Travel
}

\author{
Pooja Arora ${ }^{\circledR}$, Sumit Mrig ${ }^{2} \oplus$, Yaser Goldust ${ }^{3} \oplus$, George Kroumpouzos ${ }^{4,5} \oplus$, Ayşe Serap Karadağ $\breve{g}^{6}$, \\ Lidia Rudnicka ${ }^{7}$, Hassan Galadari ${ }^{8} \odot$, Jacek C Szepietowski ${ }^{9} \oplus$, Vito Di Lernia ${ }^{10}$, Andy Goren ${ }^{11} \odot$, \\ Martin Kassir ${ }^{12}$, Mohamad Goldust ${ }^{13}$ (])
}

\begin{abstract}
${ }^{1}$ Department of Dermatology, Post Graduate Institute of Medical Education and Research (PGIMER) and Dr. Ram Manohar Lohia Hospital, New Delhi, India ${ }^{2}$ Department of Ear Nose and Throat, Max Smart Super-Speciality Hospital, New Delhi, India

${ }^{3}$ Department of Architecture, University of Mazandaran, Faculty of Art and Architecture, Babolsar, Iran

${ }^{4}$ Department of Dermatology, Alpert Medical School of Brown University, Providence, Rhode Island, USA

${ }^{5}$ Department of Dermatology, Medical School of Jundiaí, São Paulo, Brazil

${ }^{6}$ Department of Dermatology and Venereology, İstanbul Medeniyet University School of Medicine, Göztepe Training and Research Hospital, İstanbul, Turkey ${ }^{7}$ Department of Dermatology, Medical University of Warsaw, Warsaw, Poland

${ }^{8}$ College of Medicine and Health Sciences, United Arab Emirates University, Al Ain, United Arab Emirates

${ }^{9}$ Department of Dermatology, Venereology and Allergology, Wroclaw Medical University, Wroclaw, Poland

${ }^{10}$ Dermatology Unit, Arcispedale Santa Maria Nuova, Azienda USL-IRCCS di Reggio Emilia, Italy

${ }^{11}$ Applied Biology, Irvine, California, USA

${ }^{12}$ Worldwide Laser Institute, Dallas, USA

${ }^{13}$ Department of Dermatology, University Medical Center of the Johannes Gutenberg University, Mainz, Germany
\end{abstract}

The third outbreak of coronavirus in the form of the COVID-19 infection started in Wuhan, China, in December 2019. The early and rapid spread of this infection across borders can be largely attributed to international air travel that has become a part of modern globalization. In this article, we analyze the spread of the novel coronavirus
(SARS-CoV-2) along the routes of international travel, both by air and by sea. Pitfalls of various screening methods used at the airports and the importance of optimal aircraft ventilation are discussed. Also, we suggest measures that can be taken to reduce the risk of transmission associated with air travel.

\section{INTRODUCTION}

For the third time in the last 2 decades, the world is witnessing an epidemic that has changed the way we live. The coronavirus, which was considered a non-fatal virus till the year 2002, gave rise to an outbreak of severe acute respiratory syndrome (SARS), followed by the Middle East respiratory syndrome almost a decade later. ${ }^{1}$ Just 8 years after the last outbreak, another infection emerged in December 2019 in Wuhan, China, called COVID-19, which has spread much faster than the previous outbreaks. Rapid urbanization, disruption of animal habitats, and increased animalhuman contact have created the conditions for increasing spillover events where animal viruses have crossed the species barrier to infect humans. Nowadays, humans are extensively connected due to the size and reach of the current global travel network via land, sea, and air. While this has worked in our favor in terms of globalization and growth, it has provided, at the same time, a route for these emerging respiratory pathogens to disperse easily, widely, and rapidly beyond control. In this article, we analyze how the severe acute respiratory syndrome-coronavirus 2 (SARS-CoV-2) spread from its epicenter in Wuhan, China, to other cities, and ultimately to all continents due to the extensive travel network. We also assess the various factors that affect spread of the virus during these modes of travel, especially the air route that is used widely.

Address for Correspondence: Mohamad Goldust, Department of Dermatology, University Medical Center of the Johannes Gutenberg University, Mainz, Germany e-mail:mgoldust@uni-mainz.de

Received: March 12, 2021 Accepted: April 26, $2021 \cdot$ DOI: 10.5152/balkanmedj.2021.21074

Available at www.balkanmedicaljournal.org

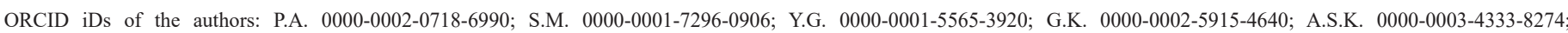

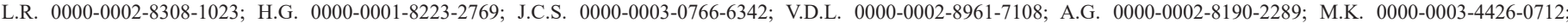
M.G.0000-0002-9615-1246.

Cite this article as:

Arora P, Mrig S, Goldust Y, et al. New coronavirus (SARS-CoV-2) crossing borders beyond cities, nations, and continents: Impact of international travel. Balkan Med J. 2021;38(4):205-211.

Copyright@Author(s) - Available online at http://balkanmedicaljournal.org/ 
Our review was based on articles that have studied or analyzed the impact of international travel by air or sea. This was done by carrying out a PubMed search with the terms "coronavirus, COVID19, international travel, transmission, screening, airports, aircrafts, maritime, ship." We studied the spread of the coronavirus SARSCoV-2 from China to other countries. We also analyzed various factors that have caused the amplification of the pandemic due to international travel, and various screening methods that have been employed to deal with the same.

\section{SPREAD FROM WUHAN TO OTHER STATES IN CHINA}

Wuhan is China's 10th largest city and a major transportation hub connecting other cities. It is known as the "Nine Provinces Thoroughfare" or "Chicago of China" due to its major role in domestic transport.

Unfortunately, the timing of the COVID-19 outbreak in Wuhan, located in the Hubei province of China, coincided with the onset of the Spring Festival. This occasion celebrates the beginning of New Year on the traditional Chinese calendar and marks the onset of the spring season. The Spring Festival started on Saturday, January 25, 2020. With the sudden outbreak of SARS-CoV2 infection and the number of cases reaching a few hundreds, the central government imposed a lockdown in Wuhan on January 23, 2020. However, it is estimated that about 5 million people had already left the city before the lockdown. The main destination of the travelers were other cities within the Hubei province and neighboring provinces. Recent analysis indicated a strong correlation between travelers' departure from Wuhan just before the start of the Spring Festival, and the extent of infection amplification in China. ${ }^{2,3}$ More than two-thirds (69.34\%) of these travelers visited other cities in Hubei province and these areas thus accounted for $54.98 \%$ of the total number of cases up to that point. Therefore, it can be deduced that travelers departing from Wuhan were the main source of infection to other cities in China.

\section{SPREAD TO OTHER COUNTRIES EARLY INTERNATIONAL SPREAD}

On January 3, 2020, Thailand implemented measures for screening of all passengers traveling from Wuhan. The first 2 cases of the COVID-19 infection in Thailand were identified on January 8 , 2020 and January 13, 2020 at the Bangkok Suvarnabhumi Airport. These were independent introductions of the infection on separate flights from Wuhan, identified with thermal scanner screening and confirmed with reverse transcriptase polymerase chain reaction (RT-PCR) testing. These 2 patients were not linked to the Huanan seafood market, which indicates that community spread had possibly already occurred within Wuhan in the first week of January. ${ }^{4}$

A situation report published by the World Health Organization (WHO) on January 24, 2020 reported 11 confirmed cases of COVID-19 infection outside China in 6 countries namely Thailand, South Korea, Vietnam, Japan, Singapore and the United States. Of these 11 cases, 10 had travel history to Wuhan, and
1 patient in Vietnam was a family member of a confirmed affected person who had visited Wuhan (WHO, 2020). ${ }^{5}$ Analysis of 2018 passenger data originating from Wuhan International Airport between January and March found that Bangkok, Hong Kong, Tokyo, and Taipei received the largest number of passengers, explaining the fact that by January 28, 2020, Thailand, Hong Kong, and Japan confirmed the largest number of cases outside China. ${ }^{6}$

The initial cases in Europe were confirmed in France on January 24, 2020, and involved a group of Chinese who had traveled to France from China around mid-January, starting the chain of case spread in European countries. ${ }^{7}$ The chronology of events in the spread of SARS-CoV-2 infection have been highlighted in Figure 1.

\section{TRANSMISSION THROUGH MARINE TRAVEL}

The shipping industry plays an important role in transportation of goods and essential commodities. Also, commercial maritime transport continues to be an important means of travel in spite of the invention of new modes of travel. It is a low-cost and efficient means of transport, especially for people in developing countries.

However, ships provide an excellent environment for transmission of infectious diseases owing to the high population density within the confined space of a vessel. This fact is best exemplified by the Cruise Ship Princess Diamond that saw the largest coronavirus outbreak outside of mainland China in February 2020. The route taken by the cruise ship — with key events - are depicted in Figure 2.

The cruise ship departed from the Port of Yokohama in Japan on January 20, 2020 and traveled to the ports of Hong Kong, Vietnam, and Taiwan, and arrived back at the Port of Yokohama in Japan on February 4, 2020 when the index case was confirmed to be positive by RT-PCR testing for COVID-19. ${ }^{8}$ The passenger had traveled in the cruise from January 20, 2020 to January 24, 2020 and disembarked in Hong Kong. All the passengers and crew were quarantined on the ship and their health status was checked through questionnaires. They were instructed to stay in the cabin and only allowed to go out for 1 hour per day. On February 19, 2020, when the quarantine ended, 619 of the 3700 passengers (17\%) were found to be positive. All positive passengers were shifted to Japanese hospitals. ${ }^{9}$

The Princess Diamond cruise ship provided a homogenously mixed population for amplified transmission of infection. Model analysis has shown that the population density on the ship was 4 times higher than in the urban city of Wuhan, and was the major factor found to affect $R_{0}$ which was 4 times higher. This led to the conclusion that $\mathrm{R}_{0}$ and contact rate are dependent on the population density and the latter should be taken into account in future modeling analyses of COVID-19 outbreak in different settings. Without the intervention by the Japanese officials, an additional 2307 people would have been infected due to the high $\mathrm{R}_{0}$. Another study has shown that most of the infections on the ship occurred 
December 31, 2019: China alerted WHO to several cases of unusual pneumonia in Wuhan, Hubei, China January 1, 2020: Huanan Seafold Wholesale Market was shut down January 7, 2020: A new virus was identified, named 2019-nCoV January 11, 2020: China announced first death

January 8 and 13,2020: Two cases were reported in Thailand, the first outside of China

January 17-24,2020: South Korea, Vietnam, Japan, Thailand, Singapore and the US confirmed cases

January 23, 2020: The cities of Wuhan, Xiantao and Chibi in Hubei province were placed under effective quarantine

January 24, 2020: The first European case was confirmed in France

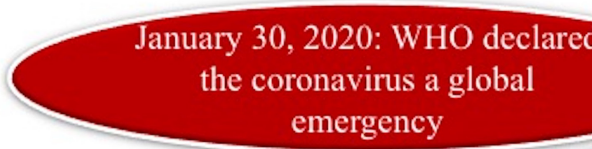
the

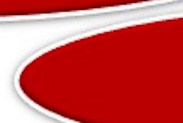

\section{March 11, 2020: WHO declared COVID-19 a pandemic}

FIG. 1. Chronology of events in the spread of SARS-CoV-2 infection.

before or around the start of the 2-week quarantine period, which highlights the importance of asymptomatic transmission among the passengers. ${ }^{10}$

\section{TRANSMISSION THROUGH AIR TRAVEL}

Air travel has become the fastest means of transportation in today's world. Simultaneously, it has allowed rapid spread of various infectious disorders, especially those that are airborne. Risk of infection varies with the type of exposure, which will be different on an aircraft compared to the risk at the airport.
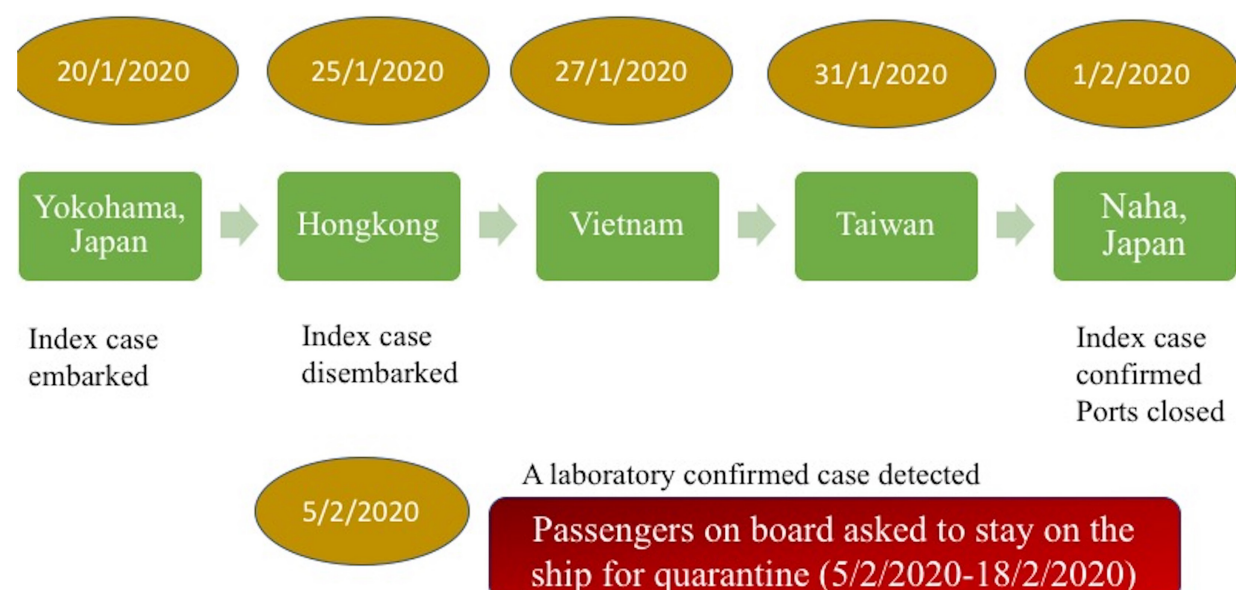

Index case confirmed

Ports closed

A laboratory confirmed case detected

Passengers on board asked to stay on the ship for quarantine $(5 / 2 / 2020-18 / 2 / 2020)$

FIG. 2. Route taken by the Cruise Ship Princess Diamond, with important key events. 
contaminated fomites like tray tables, seatbelts, overhead cabins, and washrooms, or due to movement of passengers closer together during the flight. There are other factors that affect the transmission risk such as: duration of the flight, number of infected persons (passengers) on board and their stage of illness, size of the aircraft, and type of air-ventilation system used. Factors that determine the transmission of novel coronavirus infection within an aircraft are listed in Table 1.

It has been shown recently that airborne transmission is a significant mode of infection in indoor environments and transmission can be reduced by removal of the viral droplets from indoor air via ventilation. $^{12}$

There is a laminar air circulation pattern inside commercial aircrafts, with air entering the cabin from overhead, circulating across the plane, and going out near the floor with longitudinal airflow. This laminar air circulation limits the spread of airborne particles within the cabin by dividing the airflow into sections within the cabin. The cabin air system operates by delivering $50 \%$ outside air and 50\% filtered recirculated air. The recirculated air passes through high efficiency particulate air (HEPA) filters, is mixed with fresh air in the mixing unit and then passed into cabins and circulated. The HEPA filters remove $99.97 \%$ of particles and airborne contaminants including bacteria and viruses. ${ }^{13}$ Moreover, a single air exchange removes $63 \%$ of airborne organisms suspended in that space. The air-exchange rate inside a cabin is around 15-20 changes per hour with a ventilation capacity of 10 $(4.7 \mathrm{~L} / \mathrm{S})$ cubic feet per minute. ${ }^{14}$ This ventilation system, along with a laminar flow pattern within the cabin with frequent air exchanges, and the use of HEPA filters, limits the transmission of infection. The transmission can be accelerated if there is a nonoperational ventilation system.

Nevertheless, transmission of SARS-CoV-2 is possible within aircraft, though the risk of infection spread among passengers or crew may be relatively low during short flights with a good ventilation system. $^{15,16}$

TABLE 1. Factors that Determine the Spread of Coronavirus (SARS-CoV-2) Within an Aircraft.

Seated in the Same Row or Within 3 Rows as Affected Patient
Contact with contaminated fomites (tray tables, seatbelts, overhead cabins,
and washrooms)
Movement of passengers closer together during the flight
Long duration of flight
High number of infected persons on board
Infected persons with high viral load
Size of aircraft
Type of air-ventilation system
Sitting with asymptomatic carriers
Antipyretic use by an infected patient, preventing detection with a thermal
scanner
Host related factors: general health and immune status

\section{EFFECT OF AIRPORT SCREENING AND INFECTION CONTROL MEASURES}

Use of Thermal Scanners

Thermal scanning or body temperature screening is the tool used at airports for detecting symptomatic patients with infection. However, there are major pitfalls. This is a type of symptomatic surveillance; hence, it misses travelers incubating the disease or asymptomatic carriers. Passengers can fly any time within the incubation period of the disease and become a source of infection to others, especially as the incubation period of COVID-19 is long and variable. Based on the analysis of family transmission, 1 in 6 infections can be asymptomatic and still pose a risk for seeding infection chains. ${ }^{17}$ Furthermore, the proportion of subclinical cases varies among different age groups. Most data published worldwide have shown that children and young adults, that is, those who are less than 20 years old, are under-represented - raising the possibility of a large number of subclinical cases in this age group. ${ }^{18}$

A model analysis carried out by Quilty et al. ${ }^{19}$ has shown that $46 \%$ of infected travelers screened with thermal scanners will not be detected, depending on the incubation period, proportion of cases, and sensitivity of exit and entry screening. Some reports have shown that few travelers passed the symptom-based screening at the airport and tested positive for COVID-19 by RT-PCR. ${ }^{20}$ Moreover, fever abates when the affected person takes antipyretics and hence, cannot be detected via thermal scanning.

Though fever is the most common symptom of COVID-19, a small percentage of patients do not develop fever. This is unlike SARS$\mathrm{CoV}-1$ that generally caused fever before becoming transmissible, thus enabling fever to be used as a marker to track it. ${ }^{21,22}$

Hence, it can be concluded that temperature screening alone at airports is not an effective method to minimize international spread.

\section{Health Declarations}

Health declaration forms provide information about the health status of travelers and their contact with infected people and identifies symptoms that are not visible. However, criteria used in a declaration form should be more inclusive and not restrictive, in order to be effective in detecting infected patients. Health declaration forms from passengers at arrival with contact details help in contact tracing, if needed.

Questionnaire-based screening is effective only if risk factors with high sensitivity and specificity for the disease are known, which is currently not the case for this novel virus. Only a minority of infected asymptomatic travelers would realize that they have been exposed. Moreover, analysis has shown that only $25 \%$ of travelers report truthfully the facts showing an elevated exposure risk. ${ }^{23}$ Additionally, it can lead to false identification of travelers who have symptoms due to other viral pathogens and this can lead to unnecessary travel delays. Thus, declaration forms and questionnaires seem more useful for contact tracing rather than screening at the airports. They also raise awareness among people about what precautions should be taken, if symptoms develop later. 


\section{SCREENING BY MEDICAL EXAMINATION AND LABORATORY TESTING}

After identification of infected travelers by screening measures, medical examination and laboratory testing can be conducted based on availability of resources. However, such a strategy has its own limitations in the later stages of the pandemic as it needs deployment of regular medical personnel, creating shortage in other important areas in the country. ${ }^{24}$

Rapid antigen testing can be used to screen potentially infected passengers who can then be quarantined at the destination in case of a positive result. The result can be available in 20 minutes (compared to RT-PCR that takes 8-12 hours) and avoid travel delays. The limitations of rapid antigen testing include its lower sensitivity (possibility of false negative results) and the cost factor. These should be considered while using this test as a screening tool.

Few airports have already adopted testing facilities within their locations. Examples include Frankfurt, Munich, Vienna, and Istanbul international airports. Hongkong was the world's first airport to introduce mandatory COVID-19 testing for passengers from highrisk areas.

Systematic, rapid testing of international travelers can help in resuming travel and avoid mandatory quarantine and losses due to slowdown of the global economy. Whether testing becomes "the new norm" before flying is difficult to ascertain due to the high economic burden and limitations of the currently available rapid antigen test.

\begin{abstract}
Advisories
Advisories regarding symptoms of disease, the risk factors associated with spread, and preventive measures can be issued by the respective governments and the $\mathrm{WHO}$, and are likely to affect travel behavior. It is prudent to issue advisories to avoid traveling to epidemic areas. This is especially important for the elderly and patients with co-morbidities. ${ }^{25}$

However, the effectiveness of such measures cannot be ascertained. Nevertheless, advisories form a low-cost strategy that neither inconveniences travelers nor burdens the health authorities.
\end{abstract}

\section{Isolation and Quarantine}

Potentially infected passengers can be identified and isolated to prevent the spread of infection. This can be done during flights too, using universal precaution kits and personal protective equipment. ${ }^{26}$ On the other hand, quarantine of contacts of infected travelers can delay the spread but at the same time cause inconvenience and delays. It also requires resources and preparation.

\section{Contact Tracing}

According to the Centers for Disease Control and Prevention (CDC), close contact is defined as "passengers on an aircraft sitting within 2 seats (in any direction) of the case, travel companions, anyone providing care, crew members working in the same section." ${ }^{27}$ Tracing of contacts requires considerable resources and preparation and close cooperation between public health services.
It also needs compliance on the part of contacts and might be inconvenient for passengers.

\section{Hygiene Measures}

Hygiene measures include disinfection of airports and aircrafts, frequent cleaning of public areas (toilets, gates, etc.), cleaning of frequently touched surfaces, personal hygiene (respiratory and hand hygiene), and use of facial masks. High-touch areas such as stairs, tables, chairs in restaurants and terminals, check-in screens, tray tables, bench armrests, and handles should be cleaned regularly. Self-cleaning solutions can be used for disinfection of security trays.

Using advanced and contactless technologies for disinfection can effectively reduce spread of the virus. These include mandatory online check-ins, replacing fingerprint biometric authentication with other means (face recognition etc.), installation of self-sanitizing lavatory using ultraviolet light, robotic systems for dirt detection, and use of touch-free hand-washing systems.

A study evaluated the efficacy of hand hygiene as a mitigation strategy against spread of COVID-19 using epidemiological modeling and data-driven simulations. ${ }^{28}$ It was found that increasing hand hygiene behavior of travelers at all airports can inhibit spread of the pandemic by $24 \%-69 \%$. Moreover, 10 influential locations/ airports were identified where increasing the hand-washing rate could lead to a drop of up to $37 \%$.

The effectiveness of hand hygiene measures depends on compliance of the passengers. These require resources but are not inconvenient to practice.

\section{Travel Restrictions and Border Control Measures}

Wells and colleagues have shown that the daily risk of exporting at least one SARS-CoV-2 case from China via international travel exceeded $95 \%$ on January $13,2020 .{ }^{29}$ Without the travel restrictions enforced by the Chinese government, 779 cases would have been exported by February 15, 2020. These measures averted the export of $70.5 \%$ of these cases. Also, during the early stage of the epidemic, these restrictions decreased the daily rate of export by $81 \%$ on an average. This proved beneficial in countries which were unaffected by COVID-19, because delaying the import of cases provided time to prepare for the infection.

One of the reasons for the exponential rise of cases in Europe was the delay in measures taken by the respective governments to curb air travel. Italy and Spain closed the airports only after cases had exceeded thousands, compared to China that shut down flights out of Hubei province when there were only 500 cases reported worldwide. European travel appears to have facilitated the spread of coronavirus to several other countries.

\section{OTHER FACTORS AFFECTING SPREAD THROUGH AIR TRAVEL}

\section{Characteristics of the Destination Country}

Whether an infection will be halted or allowed to spread depends also on the characteristics of the destination country. Relevant in 
this context is the Infectious Disease Vulnerability Index which measures the country's capacity to manage infectious disease threats. It utilizes various indicators including demography, health care system specifics, and political and economic metrics. Higher scores indicate a greater capacity to deal with epidemic threats. Many African countries (e.g., Nigeria, Ethiopia, Sudan) that have moderate risk of import and high vulnerability need to step up their preparedness and devise appropriate measures promptly to combat the virus. ${ }^{30}$

\section{The Way Forward}

- Based on the analysis above, the following measures can be suggested to reduce international spread of the novel coronavirus. It is important to emphasize here that these measures are dynamic and their implementation varies with the stage of the pandemic in a particular country. ${ }^{31}$

- Early ban of flights to and from severely affected countries to reduce the import of infection into minimally affected countries.

- Social distancing and thermal scanning measures should begin before passengers enter the airport. Queues should be strictly managed with appropriate distance between people.

- Arrival screening can delay the introduction of cases in regions where infection is not reported, that is, in the early stages of pandemic. This can be helpful for controlling resurgence in countries that have controlled the infection (e.g., New Zealand). In countries where local transmission has begun, it can restrict the chains of transmission. In regions with widespread ongoing transmission, departure screening will help prevent export of cases to new areas. ${ }^{23}$

- Regular sanitization and fumigation of airport terminals should include not only the arrival gates, counters, buses, and other areas handling passengers but also food and beverage outlets.

- Separate counters should be provided for flyers from affected countries. Such passengers should be channeled from gate to health screening zone. Apart from thermal screening, which should be mandatory and strictly implemented, such travelers should be asked to fill in a detailed self-declaration form so that contact tracing can be done. Health alert cards can be issued by the authorities.

- Aircrafts should be vigorously sanitized when passengers are not on board. Head cover of seats should be changed regularly. On in-transit flights, lavatories and galleys should be fumigated. The availability of in-flight magazines and duty-free services should be discontinued to reduce fomite transmission.

- All staff working at airports, especially the crew, should be given formal training on recommended guidelines and precautions. Gloves, mask, and protective eye gear should be worn at all times by crew members. ${ }^{32}$
- Sanitizers should be used by all passengers on the entry to the aircraft. Masks should be made mandatory for all travelers. It is advisable to leave middle row seats unoccupied. Though this might mean an economic burden on the airlines, it could significantly reduce the transmission within the aircraft.

- With the availability of rapid-PCR tests, cases can be identified based on questionnaire responses. ${ }^{33}$ However, this can prove expensive as such measures should be implemented on a large scale. Alternatively, smartphone-based surveillance using various applications can be done. Various governments have utilized surveillance tools that use location data via smartphones and data from mobile networks.

\section{Limitations}

The current pandemic is a dynamic and evolving situation with various factors like virus mutation, vaccination, seasonal variation, and host immunity affecting the disease spread. The measures discussed in our review are based on the current evidence on pathogenesis of the coronavirus and will need reappraisal depending on the stage of the pandemic and based on data emerging from more studies.

International travel has enabled rapid transmission of the novel coronavirus across borders. Travel restrictions and sealing off borders do work but only if implemented in the early stage of epidemic transmission. These restrictions have to be paired with various measures to decrease transmission, like public health interventions and behavioral changes. To control the outbreak, control measures would need to block more than $60 \%$ of transmission. The basic reproduction rate needs to be reduced to 1 , to control the pandemic. This can happen only with behavioral changes and social distancing. With the relaxation of lockdown measures and resumption of international travel, individuals are faced with an important decision on whether to resume traveling or remain confined. In the absence of an effective vaccine, it is crucial for people to make responsible choices, defer traveling when sick, as well as avoid all non-essential traveling amidst a pandemic.

Ethics Committee Approval: N/A.

Patient Consent for Publication: N/A.

Author Contributions: Writing - P.A., S.M.; Critical review - Y.G., G.K., A.S.K., L.R., H.G., J.C.S., V.D.L., A.G., M.K.; Final Revision and Critical Review - M.G.

Conflict of Interest: The authors have declared that no conflicts of interest exist.

Funding: The authors declared that this study had received no financial support.

\section{REFERENCES}

1. Arora P, Jafferany M, Lotti T, Sadoughifar R, Goldust M. Learning from history: coronavirus outbreaks in the past. Dermatol Ther. 2020;33(4):e13343. [CrossRef]

2. Zhong P, Guo S, Chen T. Correlation between travellers departing from Wuhan before the Spring Festival and subsequent spread of COVID-19 to all provinces in China. $J$ Travel Med. 2020;27(3):taaa036. [CrossRef]

3. Sun G-Q, Wang S-F, Li M-T, et al. Transmission dynamics of COVID-19 in Wuhan, China: effects of lockdown and medical resources. Nonlinear Dyn. 2020;101(3):19811993. [CrossRef] 
4. Okada P, Buathong R, Phuygun S, et al. Early transmission patterns of coronavirus disease 2019 (COVID-19) in travellers from Wuhan to Thailand, January 2020. Euro Surveill. 2020;25(8). [CrossRef]

5. World Health Organization (WHO). Novel coronavirus (2019-.nCoV) Situation Report - 24 January 2020. 2020. (Available at: https://www.who.int/docs/default-so urce/coronaviruse/situation-reports/20200124-sitrep-4-2019-ncov.pdf?sfvrsn=9272d 086_8\#: :text $=$ Of $\% 20$ the $\% 20830 \% 20$ confirmed $\% 20$ cases, $265 \% 20$ cases $\% 20$ si nce $\% 20$ the $\%$ 20last)

6. Bogoch II, Watts A, Thomas-Bachli A, et al. Potential for global spread of a novel coronavirus from China. J Travel Med. 2020;27(2):pii: taaa011. [CrossRef]

7. Bernard Stoecklin S, Rolland P, Silue Y, et al. First cases of coronavirus disease 2019(COVID-19) in France: surveillance, investigations and control measures, January 2020. Euro Surveill. 2020;25(6). (PubMed: [CrossRef]) [CrossRef]

8. Mizumoto K, Chowell G. Transmission potential of the novel coronavirus (COVID19) onboard the diamond Princess Cruises Ship, 2020. Infect Dis Modell. 2020;5:264270. [CrossRef]

9. Rocklöv J, Sjödin H, Wilder-Smith A. COVID-19 outbreak on the Diamond Princess cruise ship: estimating the epidemic potential and effectiveness of public health countermeasures. J Travel Med. 2020;27(3):taaa030. [CrossRef]

10. Mizumoto K, Kagaya K, Zarebski A, Chowell G. Estimating the asymptomatic proportion of coronavirusdisease 2019 (COVID-19) cases on board the Diamond Princess cruise ship, Yokohama, Japan, 2020. Euro Surveill. 2020;25(10). (PubMed: [CrossRef]) [CrossRef]

11. Olsen SJ, Chang HL, Cheung TY, et al. Transmission of the severe acute respiratory syndrome on aircraft. $N$ Engl J Med. 2003;349(25):2416-2422. [CrossRef]

12. Morawska L, Cao J. Airborne transmission of SARS-CoV-2: the world should face the reality. Environ Int. 2020;139:105730. [CrossRef]

13. Christopherson DA, Yao WC, Lu M, Vijayakumar R, Sedaghat AR. High-efficiency particulate air filters in the era of COVID-19: function and efficacy. Otolaryngol Head Neck Surg. 2020;163(6):1153-1155. [CrossRef]

14. Mangili A, Gendreau MA. Transmission of infectious diseases during commercial air travel. Lancet. 2005;365(9463):989-996. [CrossRef]

15. Zhang XA, Fan H, Qi RZ, et al. Importing coronavirus disease 2019 (COVID-19) into China after international air travel. Travel Med Infect Dis. 2020;35:101620. [CrossRef]

16. Wilson ME. What goes on board aircraft? Passengers include Aedes, Anopheles, 2019-nCo-V, dengue, Salmonella. Travel Med Infect Dis. 2020;33:101572. [Epub $2020 \mathrm{Feb}$ 5] [CrossRef]

17. Chan JF-W, Yuan S, Kok KH, et al. A familial cluster of pneumonia associated with the 2019 novel coronavirus indicating person-to-person transmission: a study of a family cluster. Lancet. 2020;395(10223):514-523. [CrossRef]

18. The Novel Coronavirus Pneumonia Emergency Response Epidemiology Team. The epidemiological characteristics of an outbreak of 2019 novel coronavirus diseases (COVID-19) in China. Zhonghua Liu Xing Bing Xue Za Zhi. 2020;41(2):145-151. [CrossRef]
19. Quilty BJ, Clifford S, Flasche S, Eggo RM. CMMID nCoV working group. Effectiveness of airport screening at detecting travellers infected with novel coronavirus(2019nCoV). Euro Surveill. 2020;25(5):2000080. [CrossRef]

20. Hoehl S, Rabenau H, Berger A, et al. Evidence of SARS-CoV-2 infection in returning travellers from Wuhan, China. $N$ Engl J Med. 2020;382(13):1278-1280. [CrossRef]

21. Wilson ME, Chen LH. Travellers give wings to novel coronavirus (2019-nCoV). $J$ Travel Med. 2020;27(2):pii: taaa015. [CrossRef]

22. Petersen E, Koopmans M, Go U, et al. Comparing SARS-CoV-2 with SARS-CoV and influenza pandemics. Lancet Infect Dis. 2020;20(9):e238-e244. [Epub ahead of print] [CrossRef]

23. Gostic K, Gomez AC, Mummah RO, Kucharski AJ, Lloyd-Smith JO. Estimated effectiveness of symptom and risk screening to prevent spread of COVID-19. eLife. 2020 ;9:e55570. [CrossRef]

24. Gaber W, Goetsch U, Diel R, Doerr HW, Gottschalk R. Screening for infectious diseases at international airports: the Frankfurt model. Aviat Space Environ Med. 2009;80(7):595-600. [CrossRef]

25. Graham A, Kremarik F, Kruse W. Attitudes of ageing passengers to air travel since the coronavirus pandemic. J Air Transp Manag. 2020;87:101865. [CrossRef]

26. Webster $\mathrm{CH}$. Airline operating realities and the global spread of infectious diseases. Asia Pac J Public Health. 2010;22(3)(suppl):137Se43S. [CrossRef]

27. Centers for Disease Control and Prevention. Operational considerations for adapting a contact tracing program to respond to the COVID-19 pandemic. 2020. [Accessed October 3, 2020] (Available at: https://www.cdc.gov/coronavirus/2019-ncov/global-c ovid-19/operational-considerations-contact-tracing.html)

28. Nicolaides C, Avraam D, Cueto-Felgueroso L, González MC, Juanes R. Hand-hygiene mitigation strategies Against global disease spreading through the air transportation network. Risk Anal. 2020;40(4):723-740. [Epub 2019 Dec 23] [CrossRef]

29. Wells CR, Sah P, Moghadas SM, et al. Impact of international travel and border control measures on the global spread of the novel 2019 coronavirus outbreak. Proc Natl Acad Sci U S A. 2020;117(13):7504-7509. [CrossRef]

30. Gilbert M, Pullano G, Pinotti F, et al. Preparedness and vulnerability of African countries against importations of COVID-19: a modelling study. Lancet. 2020;395(10227):871-877. [CrossRef]

31. Centers for Disease Control and Prevention. Public health guidance for potential COVID-19 exposure associated with international travel or cruise travel. 2020. [Accessed July 26, 2020] (Available at: https://www.cdc.gov/coronavirus/2019-ncov/ php/risk-assessment.html)

32. Chu DK, Akl EA, Duda S, et al. COVID-19 Systematic Urgent Review Group Effort (SURGE) study authors. Physical distancing, face masks and eye protection to prevent person-to-person transmission of SARS-CoV-2 and COVID-19: a systematic review and meta-analysis. Lancet. 2020;395(10242):1973-1987. [CrossRef]

33. Carter LJ, Garner LV, Smoot JW, et al. Assay techniques and test development for COVID-19 diagnosis. ACS Cent Sci. 2020;6(5):591-605. [CrossRef] 